Revue d'histoire de l'Amérique française

6. REVUE D.HISTOIRE DE L'AMÉRIQUE FRANÇAISE

\title{
La Dominique pendant l'occupation française (1778-1784)
}

Joseph-A. Boromé

Volume 23, numéro 4, mars 1970

URI : https://id.erudit.org/iderudit/302933ar

DOI : https://doi.org/10.7202/302933ar

Aller au sommaire du numéro

Éditeur(s)

Institut d'histoire de l'Amérique française

ISSN

0035-2357 (imprimé)

1492-1383 (numérique)

Découvrir la revue

Citer cet article

Boromé, J.-A. (1970). La Dominique pendant l'occupation française (1778-1784).

Revue d'histoire de l'Amérique française, 23(4), 525-557.

https://doi.org/10.7202/302933ar d'utilisation que vous pouvez consulter en ligne.

https://apropos.erudit.org/fr/usagers/politique-dutilisation/ 


\section{LA DOMINIQUE PENDANT L'OCCUPATION FRANÇAISE (1778-1784)*}

En 1778, répondant à l'appel de l'habile diplomate Benjamin Franklin et cédant à un secret désir de venger l'humiliante défaite de 1763, la France se joignit aux colonies de la NouvelleAngleterre qui voulaient s'affranchir de la domination britannique. Le théâtre des opérations s'étendit jusqu'aux Antilles où les Français rêvaient de reprendre d'anciennes possessions, et en particulier l'île de la Dominique. Le marquis de Duchilleau, colonel-commandant du Régiment Viennois à la Martinique, avait depuis longtemps souligné la valeur stratégique de cette petite île. Selon lui, elle pouvait faciliter les communications entre la Martinique et la Guadeloupe, et empêcher les flibustiers d'y établir une base. ${ }^{1}$ Thomas Shirley, gouverneur de la Dominique, ayant constaté la vulnérabilité de l'île, s'était hâté de la fortifier, particulièrement à Cachacrou. Avant son départ pour l'Angleterre, où il se rendait en congé le 28 juillet 1778, il avait maintes fois averti ses administrés que les Français étaient sur le point de les attaquer. ${ }^{2}$ Il n'avait pas encore atteint Londres que ces derniers mettaient au point un plan pour s'emparer de la Dominique.

Le 17 août, la frégate Concorde arrive à la Martinique avec la nouvelle que les hostilités ont repris en Europe. Elle apporte aussi une lettre du Ministre de la Marine, M. de Sartine, lettre qui ordonne au gouverneur général, M. de Bouillé, de s'emparer de la Dominique à la première occasion. ${ }^{3}$ De Bouillé est déjà au

* La version originale anglaise de cet article a paru dans la livraison de janvier 1969 de The English Historical Review. Quelques compléments ont été ici ajoutés au texte anglais.

1 Duchilleau, Mémoire sur les Antilles, 15 mars 1765, (MS), Archives Nationales, Section Outre-Mer, Paris, Mémoires Généraux, Amérique Méridionale et Antilles (à l'avenir: ANOM), Carton 1, no 44.

2 Shirley à Dartmouth, 25 novembre 1774 et 3 mars 1775, (MS), Public Record Office (à l'avenir: PRO), London, CO 71/5. Shirley à Germain, 18 mai 1778, PRO, 71/7.

3 E. Chevalier, Histoire de la Marine Française pendant la Guerre de l'Indépendance Américaine (Paris, 1877), 123. Forcée d'abandonner la Dominique en 1763, la France rêvait constamment d'en reprendre possession. Quand le duc de Choiseul songea à reprendre la guerre contre l'Angleterre

Vol. XXIII, no 4 (mars 1970) 
courant de ce qui se passe dans l'île, ayant entretenu une correspondance suivie avec Thomas Chabaud Arnault, un imprimeur français qui demeure à Roseau où il a été pendant plusieurs années curateur des biens de l'Eglise. Cette charge lui avait été confiée par les Anglais au lendemain de la conquête. ${ }^{4}$ De Bouillé sait donc que les Britanniques ont construit des fortifications à divers points de l'île, qu'ils disposent “de la meilleure artillerie au monde" - 164 canons et 24 mortiers - et qu'ils s'affairent à dresser des batteries à Cachacrou, à Charlotteville ou Newton et à Roseau. Il sait aussi que ces nouvelles installations ne pourront résister à une attaque terrestre parce qu'elles ne sont pas terminées. ${ }^{5}$ Enfin, il a appris que les quelques troupes régulières de la garnison dominicaine n'ont pas été renforcées et qu'elles comptent à peine "une cinquantaine d'hommes bons pour le service". ${ }^{6}$ Alors, sachant ses forces navales inférieures à celles

en 1770, il projetait de s'emparer de plusieurs des Antilles dont la Dominique. Ce projet avait fait grande impression sur François Claude Amour, marquis de Bouillé, et il avait fait pression en ce sens à Versailles avant de rejoindre son poste de gouverneur général à la Martinique le 29 avril 1777. Moins d'un mois avant, il dépêcha une corvette pour avertir les diverses colonies britanniques de son arrivée, comme c'était la coutume; mais un officier spécialisé et un ingénieur étaient à bord avec mission d'observer les ouvrages de défense et de préparer des plans pour de futures attaques (De Bouillé, Mémoire du Marquis de Bouillé avec une Notice sur sa Vie (Paris, 1890) , 39, 41, 43). En 1777, une rumeur à l'effet que l'Angleterre aurait offert l'île de la Dominique à la Russie contre des troupes et des soldats a dû causer beaucoup de soucis aux ministres français (Mémorandum, 28 novembre 1784, (MS), Archives Nationales (à l'avenir: AN), Paris, Colonies $\mathrm{C}^{10} \mathrm{D}^{3}$ ).

4 Louis Vidale à Sydney, 25 août 1784, PRO, CO 5/185; Thomas Atwood, The History of the Island of Dominica (London, 1791), 142.

5 De Bouillé, Détail de la Conquête de la Dominique, 8 septembre 1778, ANOM, Dessins et Mémoires concernant les Antilles Etrangères, Carton II, $n^{\circ} 126$; Shirley à Germain, 18 mai 1778, Stuart à Germain, 9 septembre 1778, PRO, CO 71/7. Dans The French Invasions of Dominica (Antigua, 1932), 15, Reginald St. Johnston énumère les ouvrages de défense qui existaient en 1778.

${ }^{6}$ Chevalier (op. cit., 124) comprenait difficilement la négligence des Anglais à augmenter la garnison. L'idée maîtresse qui avait présidé à la fortification de la Dominique voulait que les ouvrages de défense soient proportionnés à l'importance de l'île et que les frais d'entretien de la garnison n'égalent ni n'excèdent les revenus de cette colonie (State of the Island of Dominica, 12 juillet 1765, (MS), William L. Clements Library, Ann Arbor, Shelburne Papers). Lord George Germain, secrétaire anglais aux colonies de 1775 à 1782, s'obstinait à suivre la ligne de conduite traditionnelle qui consistait à faire intervenir la puissance maritime de l'Angleterre. Aussi, Shirley fut-il vertement réprimandé par Germain lorsque, face à la situation critique qui régnait dans l'île, il ordonna à l'ingénieur Robert George Bruce de terminer l'installation des batteries aux frais exclusifs de la Couronne, l'Assemblée (House of Assembly) n'ayant accordé 
de l'ennemi, De Bouillé décide de prendre l'initiative avant que l'amiral Samuel Barrington, qui est à Carlisle Bay (à la Barbade), puisse arriver sur les lieux avec une flottille mixte que l'on estime à 3 vaisseaux de ligne et 12 frégates. ${ }^{7}$ Apprenant que l'un des bâtiments de Barrington mouille à Rupert's Bay, il dépêche à la Dominique, le 3 septembre, un officier du nom de Gabrouse avec mission de vérifier si le bâtiment en question est toujours au même endroit. La présence simultanée dans l'île de plusieurs Français non résidents qui viennent tous visiter des parents ou des amis, inquiète les Anglais. En l'absence de Shirley, le lieutenant-gouverneur William Stuart, qui le remplace et qui est au courant, depuis le 20 août, de la déclaration de guerre de la France et du dessein des Français d'attaquer la Dominique, ordonne l'arrestation de Gabrouse sous une accusation d'espionnage. Cependant, après l'avoir interrogé et trouvé innocent, il le relâche et lui permet de quitter l'île. ${ }^{8}$ Pendant ce temps, à la Martinique, les préparatifs de l'attaque se poursuivent en secret, car les relations avec la Dominique continuent comme à l'accoutumée. C'est ainsi que le 2 septembre De Bouillé et

aucune aide financière. Germain déclara que la défense de la Dominique ne reposait pas sur les troupes régulières (auxquelles il ne promettait aucun renfort), mais qu'elle était assurée par une flotte puissante qui croisait dans les parages. Et il ajoutait: "Tout ouvrage de défense qui ne serait pas à la portée du tir de nos vaisseaux ne servirait qu'à rendre plus difficile la tâche de déloger l'ennemi, si ce dernier réussissait à occuper les îles avant l'arrivée de notre marine" (Germain à Shirley, 2 septembre 1778, PRO, $\mathrm{CO}, 71 / 7)$. D'après le lieutenant-gouverneur Stuart, l'armée dominicaine comptait 5 officiers et 41 soldats du " $48^{\text {th }}$ Regiment" (à part les défenseurs de la batterie de Cachacrou), 18 artilleurs et environ 130 hommes de milice. Quant à De Bouillé, il évaluait les forces de l'île à quelque 120 soldats et 500 miliciens (Stuart à Barrington, 14 septembre 1778 , PRO, WO 1/51; De Bouillé, Mémoire Détaillé de mon Administration aux Isles du Vent, (MS), Bibliothèque Nationale, Paris, Nouvelles Acquisitions Françaises, $9430)$. Les articles de la capitulation du 7 septembre 1778 mentionnent 6 officiers et 94 hommes (Atwood, op. cit., 124). Bien qu'essentiellement les mêmes, les articles cités par Atwood (ibid., 123-137) diffèrent beaucoup par leur phraséologie de ceux que l'on trouve dans les procès-verbaux du Conseil privé de la Dominique (Dominica, Minutes of the Privy Council, 14 septembre 1778, (MS), Archives Room, Ministerial Building, Roseau, Dominica).

7 De Bouillé, Relation de la Prise de la Dominique, 8 septembre 1778, ANOM, Dessins et Mémoires, Carton II, $\mathrm{n}^{\circ} 124$. Ce document est presque une réplique des récits suivants du même auteur: Détail de la Conquête de la Dominique, 8 septembre 1778, ibid., Carton II, no 126; Détail de l'Expédition de la Dominique, 8 septembre 1778 , AN, Colonies $\mathrm{F}^{3} 44$. On retrouve les mêmes renseignements dans le Mémoire Détaillé (de De Bouillé), Bibl. Nat., Nouv. Acq. Fr., 9430.

8 De Bouillé, Mémoire Détaillé, ibid.; Atwood, op. cit., 109-110; Stuart à Barrington, 20 août 1778 dans l'édition Bonner-Smith, The Barrington Papers (London, 1941-1942), II : 41. 
Stuart s'engagent formellement à interdire le pillage aux flibustiers. ${ }^{9}$ Trois jours plus tard, ayant appris que Barrington a rappelé le navire qui était en rade à Rupert's Bay, De Bouillé passe à l'action avec sa rapidité coutumière..$^{10}$ Le 6 septembre, après le coucher du soleil, 1,800 soldats et 1,000 créoles volontaires - comprenant des Blancs et des Noirs affranchis s'embarquent sur "4 frégates", 10 goélettes et sloops armés et 20 transports de troupes. ${ }^{11}$ A l'aube entre 3 et 4 heures, les navires arrivent en vue du fort Cachacrou. Quelques habitants français avaient frayé la voie aux envahisseurs en s'introduisant dans le fort, en faisant boire du vin à la garnison et en jetant du sable dans le mécanisme des canons afin de les rendre inutilisables.12 En moins d'une heure le fort assiégé capitulait. L'attaque sur Cachacrou ne fit aucune victime, si l'on excepte

9 Prevost à Grenville, 12 août 1803, PRO, CO 71/36.

10 Edgar Sanderson, The British Empire at Home and Abroad (London, 1903), I: 333-334. Il était au courant de la nouvelle que 6,000 hommes faisaient route de la nouvelle-Angleterre vers les Antilles, en partie afin d'apporter du renfort à la Dominique (De Bouillé, Mémoires, 46). Pour tromper la surveillance des Anglais à la Dominique, il choisit délibérément le temps de la pleine lune où l'on considère les mers dangereuses pour la navigation.

11 De Bouillé, dans son compte rendu, Détail de l'Expédition, 8 septembre 1778, AN, Colonie $\mathrm{F}^{3} 44$, parle de 1,800 soldats; Chevalier, op. cit., 124; Stuart à Germain, 9 septembre 1778, PRO, CO 71/7. Des écrivains anglais sont portés à exagérer le nombre de soldats français. Dans une lettre à Barrington datée du 14 septembre 1778, PRO, WO, 1/51, Stuart, tout en rapportant qu'il y avait quatre frégates - en réalité il y en avait trois (L'Amphitrite, La Diligente et La Tourterelle), et une corvette, - écrit qu'environ 3,000 hommes ont pris part à l'invasion, tandis que dans une autre lettre à Germain en date du 9 septembre 1778, PRO, CO 71/7, il dit que 2,000 soldats ont participé à la seule attaque contre Roseau. Atwood, $o p$. cit., 140, et St. Johnston, op. cit., 5, font état de 3,000 réguliers et de 1,500 volontaires, tandis que Johnston rapporte que cette force était armée de 164 canons et de 24 mortiers de cuivre qu'ils ont capturés par la suite! Atwood, op. cit., 113, affirme aussi que la force ennemie comprenait en outre 3 frégates, 1 vaisseau de quarante canons et quelque 30 sloops et goélettes. De plus, il soutient que les Français avaient mis à la voile entre 3 et 4 heures du matin, le 6 septembre, mais que l'absence de vent avait retardé leur avance, même si ce sont les vents qui causèrent en réalité leur retard. Il est certain que les Français avaient escompté donner l'assaut aux premières heures du jour, avant que les Dominicains n'aient eu le temps d'organiser leur défense (Y.J. Kerguelen, Relations des Combats et des Evénements de la Guerre maritime de 1778 (Paris, 1796), 45).

12 Atwood, op. cit., 112. Dans son ouvrage Alone in the Caribbean (London, 1919), 239, Frederic A. Fenger soutient que les intrus faisaient partie des troupes françaises. Cette version est peu plausible, car il aurait fallu alors que la garnison fût déjà en état d'ébriété pour laisser les soldats français pénétrer dans la place. Il est plus vraisemblable de croire que les saboteurs étaient des habitants de l'île et non des militaires. 
les deux fantassins anglais du " $48^{\mathrm{e}}$ Regiment" qui, poussés pardessus les remparts, se tuèrent en tombant sur les rochers. ${ }^{13}$ A 4 heures et demie, les Français tirent un coup de canon de l'intérieur du fort. Quinze minutes plus tard, une autre détonation éclate et des fusées volantes éclairent le firmament: c'est un signal destiné à la "cinquième colonne". Le bruit éveille en sursaut les insulaires de la côte Sous-le-vent, qui se préparent fébrilement au combat. A Roseau, Stuart fait tirer le canon d'alerte et, après avoir rassemblé une centaine d'hommes au roulement du tambour, leur ordonne de se joindre aux quelques soldats qui défendent les fortifications et les postes d'artillerie entourant la ville. Les Français de la Dominique qui avaient répondu à l'appel du lieutenant-gouverneur disparurent bientôt comme par enchantement. Ils tenaient la promesse qu'ils avaient faite aux espions français de ne pas prendre les armes contre leurs compatriotes. On ne les revit qu'une fois le combat terminé. ${ }^{14}$ Pendant que les femmes, les enfants et les esclaves noirs pris de panique se précipitent dans les rues et traversent péniblement les rivières pour se mettre à l'abri en dehors de la ville, les défenseurs sont en butte à toutes sortes de difficultés. Ainsi, à Grey's Hill (maintenant King's Hill), deux des trois canons de la batterie se fendent. A d'autres endroits, les pièces s'affaissent dès les premières salves, parce que leurs affûts en bois sont pourris. Il faut démonter les canons et les transporter sur les remparts pour pouvoir s'en servir. Au poste Melville, à Charlotteville, on dut ainsi désassembler cinq des six pièces d'artillerie et les charger avec de la poudre en vrac, en attendant d'obtenir des gargousses du fort Young à Roseau situé à un demi-mille de là. ${ }^{15}$

En dépit de la pitoyable faiblesse numérique des forces anglaises, les Français, qui avaient projeté deux attaques principales entre Roseau et Cachacrou, ${ }^{16}$ n'eurent pas la partie facile. Entre 7 et 8 heures, ils réussirent à débarquer environ 1,400 soldats à Pointe-Michel à deux milles au sud de Roseau, mais ils perdirent 40 des leurs. A Loubière, situé plus au nord et à mi-chemin entre Pointe-Michel et Roseau, 600 Français s'emparèrent $d u$ fort non sans avoir été repoussés trois fois. Le

${ }_{13}$ Atwood, op. cit., 113; D'Arbaud au Ministre, 8 septembre 1778, ANOM, Dessins et Mémoires, Carton II, n 123 ; Stuart à Germain, 9 septembre 1778, PRO, CO 71/7.

14 Atwood, op. cit., 116. CO $71 / 7$.

15 Atwood, op. cit., 117; Stuart à Germain, 9 septembre 1778, PRO,

16 Kerguelen, op. cit., 44. 
commissaire général fut tué et De Bouillé lui-même échappa de justesse à la mort lorsqu'un boulet lui arracha l'épée qu'il portait au côté. ${ }^{17}$ Quand les troupes qui avaient donné l'assaut à PointeMichel eurent fait leur jonction avec celles de Loubière, les forces réunies marchèrent sur le fort Roseau défendu par des canons de montagne. Pendant que ces événements se déroulaient, quelque 500 hommes protégés par le tir d'une frégate débarquaient sur le rivage au nord de Roseau, et trois frégates prenaient position dans la baie afin de canonner la ville. Vers midi, de son poste d'observation au sommet de Jolly's Hill, le lieutenant-gouverneur Stuart aperçoit des soldats français, sous le vicomte de Damas, installés sur les hauteurs qui dominent la ville. Comprenant alors que la situation est désespérée, il accepte les recommandations de son Conseil privé et de quelques notables et envoie des parlementaires s'enquérir des conditions d'un cessez-le-feu. Moins d'une heure plus tard tout combat avait cessé. A 3 heures de l'après-midi, De Bouillé se présente à la résidence du gouverneur afin de régler les derniers détails de la capitulation. ${ }^{18}$ Soudain, le bruit assourdissant de deux bordées vient interrompre les discussions. C'était les canonniers de la frégate Tourterelle qui, sur l'ordre de leur capitaine, tiraient sur le fort Young. Ce commandant ne savait pas que les Anglais avaient capitulé et croyait avoir vu un drapeau ennemi flotter sur les remparts. De Bouillé et Stuart se rendent au fort en toute hâte et arrivent juste au moment où un milicien tenant une mèche enflammée s'apprête à tirer un obus de quarante-deux livres qui eût atteint la frégate de plein fouet. Du haut du parapet, les deux hommes crient à tous les commandants de frégate que les assiégés ont déposé les armes. Ils reviennent ensuite à la salle des pourparlers et, à 5 heures, ils signent l'acte de capitulation dont les clauses étaient à peu près les mêmes que celles qu'avaient signées le commodore John Moore et le brigadier général John Barrington,

17 Bryan Edwards, The History, Civil and Commercial, of the British West Indies (London, 1819), I: 437; Atwood, op. cit., 118; Stuart à Barrington, 7 septembre 1778, dans The Barrington Papers, II: 47. Stuart faisait remarquer à Germain (9 septembre 1778, PRO, CO 71/7) que les Français avaient dissimulé leurs pertes. Dans une lettre au Ministre (8 septembre 1778, ANOM, Dessins et Mémoires, Carton II, no 123), D'Arbaud, gouverneur de la Guadeloupe, déclare que les Français n'ont perdu aucun homme, et De Bouillé répète la même affirmation dans divers communiqués officiels. Dans son ouvrage Histoire politique, économique et sociale de la Martinique sous l'Ancien Régime, 1635-1789 (Paris, 1935), 150, Cabuzel Andréa Banbuck, s'inspirant de la Gazette de la Martinique (numéros des 10 et 17 septembre 1778), certifie qu'aucun homme n'a été tué.

18 D'Arbaud au Ministre, 8 septembre 1778, ANOM, Dessins et Mémoires, Carton II, $\mathrm{n}^{\circ} 123$. 
lors de la reddition de la Marie-Galante en 1759.19 La cérémonie terminée, De Bouillé se met à la tête de ses troupes et fait une entrée triomphale dans la ville. Les soldats défilent lentement dans les rues, portant à leurs tricornes des rameaux et des fleurs en signe de victoire. Selon Thomas Atwood, un gérant de plantation qui détestait cordialement les Français, les vainqueurs tentaient d'intimider les vaincus en prenant des airs terribles. ${ }^{20}$ Il n'y eut aucun pillage, car De Bouillé, qui avait imposé à la population un tribut de $£ 4,400$, remit à chacun de ses hommes une prime d'une demi-portugaise. ${ }^{21}$

Le lendemain, Rupert's Bay capitule à son tour et les vaincus s'embarquent pour l'Angleterre. De Bouillé accorda l'amnistie à tous les déserteurs français de la Dominique et de Sainte-Lucie qui n'avaient pas pris les armes contre ses troupes. ${ }^{22}$ Il devait se montrer beaucoup moins clément à l'égard de quelques armateurs anglais dont les navires faisaient la guerre aux colonies de la Nouvelle-Angleterre et capturaient les bâtiments français sous prétexte qu'ils étaient américains. ${ }^{23}$ Il leur imposa de lourdes amendes.

Peu de temps après, Stuart, triste et déçu, s'embarque pour la Barbade. Pendant un an, il sillonne les eaux des Caraïbes, espérant reprendre bientôt l'île qu'il avait perdue. Toutefois, lord Germain devait le rappeler en Angleterre avant qu'il ait pu mettre son projet à exécution. ${ }^{24}$ La chute rapide de la Domi-

19 De Bouillé reconnut cependant que les conditions imposées par les Anglais à la chute de la Guadeloupe en 1759 étaient plus généreuses que les siennes (De Bouillé au Ministre, 24 février 1779, ANOM, Dessins et Mémoires, Carton II, $\mathrm{n}^{\circ}$ 134; Réflexions sur la Capitulation Signée à la Dominique AN, Colonies, $\mathrm{F}^{3} 44$; Kerguelen, op. cit., 46).

20 Atwood, op. cit., 122. Algernon E. Aspinall, West Indian Tales of Old (London, 1912), 164. St. Johnston, op. cit., 5. Deux colonels du "St. George Regiment" (Milice) cachèrent leurs drapeaux au moment de la reddition. Quand les Anglais reprirent possession de l'île en 1784, ils arborèrent ces deux étendards, les seuls qui avaient échappé à la défaite de 1778 (Orde à North, 3 février 1784, PRO, CO 71/48).

21 Atwood, op. cit., 114; De Bouillé, Détail de la Conquête, 8 septembre 1778, ANOM, Dessins et Mémoires, Carton II, $\mathrm{n}^{\circ} 126$. Une portugaise était une pièce d'or valant trente-quatre livres.

22 Atwood, op. cit., 123, 136; Ordonnance Portant Amnistie, 8 septembre 1778, $\mathrm{AN}$, Colonies $\mathrm{C}^{10} \mathrm{D}^{3}$. De Bouillé réunit les déserteurs dans une compagnie de volontaires qui portait son nom. En 1779, ils étaient cinquante (De Bouillé à De Sartine, 8 juillet 1779, PRO, CO 166/1).

23 Atwood, op. cit., 141.

24 Germain à Stuart, 5 août 1779, PRO, CO $71 / 7$. Stuart aimait la Dominique où il avait servi en qualité de lieutenant-gouverneur de 1771 à 1778. Il avait auparavant rempli la même charge à Tobago pendant dix ans. Quelques années plus tard, la Dominique passa de nouveau sous la 
nique avait stupéfié les Anglais. ${ }^{25}$ Lord Macartney, gouverneur des îles méridionales des Caraïbes, fit la remarque "qu'un seul vaisseau de ligne aurait suffi pour sauver l'île". Il exprimait là l'opinion d'un bon nombre de ses compatriotes, aussi bien des Antilles que de la Grande-Bretagne. ${ }^{26}$ La défaite fut largement imputée à Barrington qui avait pourtant exécuté à la lettre les instructions de l'Amirauté. La Chambre des lords ordonna une enquête, mais rien ne pouvait changer quoi que ce soit au fait accompli. ${ }^{27}$ La Dominique était bel et bien aux mains de De Bouillé.

De Bouillé s'était fixé comme premier objectif de transformer l'île en un bastion imprenable et d'en faire un trait d'union important entre la Martinique et la Guadeloupe. Il ne songeait nullement à ruiner la prospérité de la Dominique, mesure qui aurait pu inciter l'Angleterre à céder cette colonie à la France à la fin des hostilités. Il n'avait pas non plus l'intention d'user de représailles à l'égard des Anglais pour la façon dont ces derniers avaient traité les vaincus de 1763 , pas plus qu'il ne se proposait d'exproprier les biens de la population anglaise ou de la priver de ses droits civiques. ${ }^{28}$ Dans les quelques jours

domination britannique et il revint occuper son ancien poste. En 1785, il paralysa du côté gauche à la suite d'une attaque d'apoplexie, puis, en 1788 , une autre crise provoqua une cécité partielle et la paralysie du côté droit. James Bruce qui lui succéda en 1789 renonça à tout traitement en faveur de son prédécesseur. Stuart mourut à la Dominique au mois de septembre de la même année (Winstone à Rae, 10 mai 1785 , Clements Library, Winstone Letterbook; Orde à Sydney, 9 juin, 30 septembre et 4 octobre 1778, PRO, CO 71/14; Bruce à Grenville, 5 août et 15 octobre 1789, PRO, CO 71/16). 25 Germain à Clinton, 13 novembre 1778, (MS), Clements Library, Germain Papers; Clinton à Knox, 4 décembre 1778, dans Great Britain, Historical Manuscripts Commission, Report, Various Collections (London, 1909), VI: 154.

26 Macartney à Germain, 31 octobre 1778, dans Great Britain, Historical Manuscripts Commission, Report, Manuscripts of Mrs. Stopford-Sackville (London, 1910), II : 119; Winstone à Chollet, 26 octobre 1778, Clements Library, Winstone Letterbook.

27 Journal of the House of Lords, 7 décembre 1778, (MS), Library of the House of Lords, London, volume 35. - John W. Fortescue, History of the British Army (London, 1911), 265, tient pour peu de chose la prise de la Dominique; il n'en fut pas de même des Français. Certains y virent comme une annonce des futurs assauts qui eurent lieu en 1779 contre St-Vincent et la Grenade, ce qui amena Louis XVI, citant les trois îles, à demander à l'archevêque de Narbonne de célébrer ces prises par le chant d'un Te Deum dans toutes les églises de sa paroisse (Magg Bros., The History of the French Colonisation of America; French Administration Acta concerning America (1581-1791) (Paris, 1936), 127).

28 Atwood, op. cit., 46, lui attribue des desseins tout à fait contraires, comme d'ailleurs James C. Moris dans Religious History of Dominica [1950], (MS), Bishop's House, Roseau, Dominica. 
qui suivirent la victoire et pendant que les Dominicains venaient de tous les coins de l'île signer les articles de la capitulation, il établit un nouveau gouvernement ayant à sa tête Marie Charles, marquis de Duchilleau. Enfin, il laissa dans l'île une garnison forte de 800 hommes (700 soldats réguliers et 100 Noirs affranchis) et retourna à la Martinique. ${ }^{29}$ De Bouillé allait regretter plus d'une fois d'avoir nommé Duchilleau au poste de gouverneur. Il avait d'abord offert cette charge au vicomte de Damas qui l'avait refusée. Détenteur du pouvoir, Duchilleau se montra obstiné, insoumis et d'un commerce désagréable. ${ }^{30}$ Aux yeux des Anglais il était la parfaite image de Néron.

Le nouveau gouverneur eut la tâche (combien difficile !) de faire de la Dominique un petit Gibraltar. Les instructions de ses supérieurs lui enjoignaient de faire régner le contentement général, de favoriser l'agriculture et le commerce et, à l'aide d'une milice recrutée parmi les habitants français, de procéder immédiatement à la fortification de l'île, de maintenir une forte garnison et d'aménager des hôpitaux militaires. En outre, il devait interdire aux Anglais de se réunir, désarmer ceux qui n'étaient pas véritablement propriétaires et exiger que tous les Britanniques, à l'exception de quelques notables, remettent leurs armes à des personnes en vue de chaque paroisse, en cas d'attaque par leurs compatriotes. Enfin, il avait reçu l'ordre de défendre aux esclaves de porter une arme. ${ }^{31}$ Chaque couche de la population, qui comptait 1,574 Blancs (dont les deux tiers étaient Français), 574 affranchis (Mulâtres et Noirs) et 14,309

${ }^{29}$ Le baron de Fagan fut nommé commandant en second, et De Beaupuy, lieutenant des fortifications. De Barthel, capitaine au Régiment Viennois, devint maire de la ville, et M. S. Linger, qui était commissaire de la Marine, se vit désigné au poste d'intendant (De Bouillé au Ministre, 8 septembre 1778, et aussi De Bouillé dans ses Instructions Pour le Marquis Duchilleau, 15 septembre 1779 [1778], ANOM, Dessins et Mémoires, Carton II, nos 125 et 138; Dominica, Privy Council Minutes, 14 septembre 1778; Gazette de la Martinique, 10 septembre 1778). Dans Four Year's Residence in the West Indies (London, 1883), 653, Frederic W. N. Bayley, se faisant l'écho des préjugés répandus parmi ses concitoyens, affirme que 5,000 Français furent laissés sur l'île. De son côté, Stuart écrit à Barrington (14 septembre 1778, PRO, WO 1/51) qu'il y en avait environ $1,500, y$ compris les 100 Noirs affranchis "et quelques miliciens de la Guadeloupe et de la Martinique". Au $1^{\text {or }}$ juillet 1779 , la garnison était passée de 800 à 1,519 hommes (De Bouillé et De Sartine, 8 juillet 1779, PRO, CO 166/1). Le $1^{\text {er }}$ juillet 1781 , elle comptait 1,527 soldats (Etat de la Situation des Garnisons, AN, Colonies $C^{8}$ A 80 ).

30 De Bouillé, Mémoire Détaillé, Bibl. Nat., Nouv. Acq. Fr., 9430.

31 De Bouillé, Instructions Pour le $\mathrm{M}^{\mathrm{is}}$ Duchilleau, 15 septembre 1779 , ANOM, Dessins et Mémoires, Carton II, no 138; une copie de ces instructions $\left(\mathrm{AN}\right.$, Colonies $\left.\mathrm{C}^{10} \mathrm{D}^{8}\right)$ porte la date de 1778. 
esclaves, allait être touchée par ces mesures. ${ }^{32}$ Bien qu'elle eût conservé ses lois, sa religion et sa forme de gouvernement, la minorité anglaise, qui avait pendant quinze ans gouverné la Dominique, se vit réduite à un état de subordination qui la rendait bien malheureuse. Ses chefs de file s'efforcèrent de collaborer malgré l'irritation que leur causait parfois l'attitude provoquante de Duchilleau. ${ }^{33}$ Néanmoins, la plupart détestaient le gouverneur et tout ce qu'il représentait. De plus, les conséquences de la guerre, qui se traduisaient par un malaise économique sans cesse grandissant en raison de la baisse considérable des importations et des exportations, ne faisaient qu'accroître l'antipathie générale.

Les Anglais eurent bientôt un avant-goût des ennuis qui les attendaient. Le 14 septembre, Duchilleau se présente à la réunion conjointe du Conseil et de l'Assemblée, afin de prononcer son premier discours officiel. Dédaignant les civilités, il ordonne aux membres présents de désarmer les esclaves noirs, de fournir des bestiaux à un prix raisonnable aux troupes d'occupation et de dresser, dans les cinq jours suivants, une liste des personnes "en vue" auxquelles les Anglais pourraient remettre leurs armes, le cas échéant. Le lendemain, les membres du Conseil se rendent chez le gouverneur et le président Alexander Stewart fait lecture d'un texte en réponse à l'allocution de la veille. Il loue les "termes de la capitulation, inspirés par des sentiments d'honneur, d'humanité et de justice", il félicite les troupes françaises pour leur

32 De Bouillé, 29 septembre 1778, AN, Colonies $C^{8}$ A 77; Stuart à Germain, 29 septembre 1778, PRO, CO 71/7.

33 Ils collaborèrent avec les Français comme le firent d'ailleurs les Anglais de Saint-Christophe et de Nevis, deux petites îles capturées en 1782. Toutefois, quelques années plus tard, ils se donnèrent beaucoup de mal pour minimiser ou même nier cette collaboration. L'ouvrage d'Arthur P. Watts, Nevis and St. Christopher's 1782-1784 (Paris, s.d.), fournit un témoignage accablant sous forme de copies de procès-verbaux des séances du Conseil pendant l'occupation française. Ces copies sont aujourd'hui la propriété de la Bancroft Library de Californie. On avait, semble-t-il, pris soin d'enlever du registre des délibérations du Conseil - maintenant au Public Record de Londres - les passages compromettants, avant que les archives ne soient envoyées en Angleterre. C'est sans doute cet habile subterfuge qui explique que les archives britanniques renferment si peu de renseignements sur l'occupation de certaines îles des Antilles pendant la Guerre de l'Indépendance. Il est évident que les procès-verbaux des séances du Conseil privé de la Dominique de 1775 à 1782 conservés à Roseau n'ont jamais été expédiés à Londres. On trouve au Public Record Office (Co 74/6B) les comptes rendus de certaines réunions du Conseil privé tenues de 1771 à 1791, mais ces comptes rendus, obtenus de particuliers en 1950 , se rapportent à une époque antérieure ou postérieure à l'occupation française. 
discipline et promet de se conformer dans la mesure du possible aux instructions de Duchilleau, y compris celle qui oblige les Anglais à se départir de leurs armes. ${ }^{34}$ Cette adresse plut tellement à De Bouillé, qui se trouvait alors à la Martinique, qu'il l'envoya immédiatement en France pour justifier la générosité avec laquelle il avait traité les vaincus et comme gage de la bonne conduite des Anglais dans l'avenir..$^{35}$

Duchilleau prit rapidement des mesures dans divers domaines. En conformité des instructions qu'il avait reçues, il institua le 17 septembre une milice qui devait se composer de Dominicains français, mais qui était formée en grande partie de Noirs affranchis. ${ }^{36}$ Cette décision déplut aux Britanniques encore irrités du pacifisme manifesté par la population française au moment de l'invasion. Craignant les complots, le gouverneur fit ouvrir les lettres personnelles et interdit le rassemblement de plus de deux Anglais à n'importe quel endroit. Il alla même jusqu'à obliger ces derniers à éteindre les lumières dans leurs maisons dès 9 heures du soir et à porter une lanterne allumée lorsqu'ils circulaient dans les rues, afin que l'on puisse suivre leurs mouvements. ${ }^{37}$ Les récalcitrants pouvaient servir de cibles aux sentinelles, être jetés en prison ou envoyés en exil. Le capitaine Robert Thou fut l'une des premières victimes de cette ordonnance. Une sentinelle interprétant à la lettre les ordres reçus le blessa mortellement au moment où il regagnait son navire après le couvre-feu. Un peu plus tard, Duchilleau, probablement alarmé par un rapport voulant que Barrington ait quitté la Barbade et fasse voile vers l'île avec une flotte imposante, et persuadé qu'il ne fallait garder que la quantité d'armes nécessaire pour se faire obéir des esclaves, enjoignit à tous les Anglais de rapporter leurs armes aux autorités. ${ }^{38}$ Cette menace d'invasion ne devait pas se concrétiser, car Barrington voyant flotter les drapeaux français retourna à Carlisle Bay. Toutefois, l'ordonnance demeure en vigueur, ce qui amène les Anglais à protester

34 Dominica, Privy Council Minutes, 14 septembre 1778; Alexander Stewart à Duchilleau, 15 septembre 1778, AN, Colonies F3 44 .

35 De Bouillé au Ministre, 17 septembre 1778, ANOM, Dessins et Mémoires, Carton II, no 128.

${ }^{36}$ De Bouillé, 9 novembre 1778, AN, Colonies C8 A 77.

37 Thomas Coke, A History of the West Indies (Liverpool, 1808), II: 340 ; St. Johnston, op. cit., 5-6. Ces deux auteurs se sont inspirés d'Atwood, op. cit., 147-148.

38 Dominica, Privy Council Minutes, 6 octobre 1778; Atwood, op. cit., 145, 148; Chevalier, op. cit., 125; De Bouillé au Ministre, 6 janvier 1779, ANOM, Dessins et Mémoires, Carton II, n 131. 
avec véhémence contre une telle violation de l'Article 18 qui permettait à la population anglaise de garder ses armes aussi longtemps que la Dominique ne serait pas attaquée. Ils ignorent cependant que De Bouillé, qui appuie la décision de Duchilleau en cette affaire, se croit pleinement justifié de modifier certaines clauses de la capitulation. En effet, le gouverneur général soutient que la veille de la reddition, alors qu'il était épuisé et tombait de sommeil, il avait signé un document sans se rendre compte que le secrétaire de Stuart y avait changé plusieurs mots d'une importance capitale. ${ }^{39}$ Il supporte aussi Duchilleau lorsque ce dernier refuse l'autorisation d'interjeter appel auprès de la Chancellerie de Londres (Article 22), qu'il interdit toute forme de communication avec la Grande-Bretagne (Articles 18, 19 et 24) et qu'il restreint le nombre des navires neutres qui peuvent entrer dans les ports de la Dominique (Article 17) .4 $^{40}$ Par contre, De Bouillé s'oppose à toute violation flagrante des clauses de la capitulation. D'une part, il désire empêcher que les Français n'apparaissent mesquins à côté des Anglais qui, eux, respectent scrupuleusement le traité signé à la Guadeloupe en 1759, et, d'autre part, il veut éviter de provoquer la population anglaise dont le comportement après la défaite ne donne aucun motif de plainte. Aussi, s'élève-t-il contre le projet de Montdenoix, intendant par intérim, qui entend réformer le système administratif de la Dominique sur le modèle de celui de la Martinique où le gouverneur général et l'intendant se partagent les pouvoirs. Montdenoix, de qui relèvent la justice, les finances et le commerce dans les îles françaises, ne contrôle que les finances à la Dominique. En gardant l'île sous le régime des lois anglaises, De Bouillé conserve au poste de gouverneur l'importance qu'il a toujours eue et se conforme à la tradition qui veut que la police relève de l'autorité locale. L'intendant, encouragé, semble-t-il, par des fonctionnaires ambitieux, se plaint constamment à De Bouillé de la trop grande influence des militaires dans l'administration des colonies. Après d'interminables querelles, il assiège le Ministre et finit par obtenir la permission de faire certains changements. Alors, à l'insu de De Bouillé, il écrit à Duchilleau lui annonçant non seulement les changements autorisés, mais

39 De Bouillé au Ministre, 17 septembre 1778, ANOM, Dessins et Mémoires, Carton II, $n^{\circ} 128$. Plus tard, le gouverneur John Orde de la Dominique informait lord North (27 février 1784, PRO, CO 71/8) que De Bouillé avait changé une partie de l'article 15 deux jours après la capitulation.

40 Dominica, Privy Council Minutes, 19 février 1779; De Bouillé au Ministre, 17 septembre 1778 et 6 janvier 1779, ANOM, Dessins et Mémoires, Carton II, no 128 et $n^{\circ} 131$. 
d'autres qui ne le sont pas. En outre, il déclare que la Dominique restera une conquête inutile aussi longtemps qu'elle sera gouvernée par les lois anglaises et il qualifie De Bouillé de despote. Duchilleau qui demeure fidèle à son supérieur, sert à Montdenoix une leçon sur l'honnêteté et envoie la lettre de ce dernier au gouverneur général. De Bouillé fait appeler Montdenoix et le réprimande "avec douceur". ${ }^{41}$ Finalement, le projet de l'intendant intérimaire est laissé de côté en attendant la signature d'un traité de paix avec la Grande-Bretagne. ${ }^{42}$

Duchilleau se montra assez habile au début de son mandat. En octobre 1778, un mois à peine après son entrée en fonction, il nomma au Conseil (formé exclusivement d'Anglais, jusque-là) un résident français, Nicolas Crocquet de Belligny. ${ }^{43}$ Il semble que les membres du Conseil aient accepté de bonne grâce cette nomination, même que le premier jour où Belligny occupa son siège de conseiller, ils eurent des mots flatteurs à l'égard de Duchilleau, l'assurant "de la parfaite estime que votre conduite nous inspire". Ils le félicitèrent de leur avoir consenti un délai pour remettre leurs armes, concession, disaient-ils, "qui s'appuie avec bonheur sur l'Affection et la Justice". Et ils ajoutaient:

Nous constatons avec beaucoup de satisfaction et de reconnaissance que vous vous préoccupez d'assurer la Paix, la Tranquillité et la bonne Administration de cette colonie et que vous édictez des règlements en ce sens. ${ }^{44}$

Avant la fin d'octobre, Duchilleau fait encore une fois bonne impression lorsqu'il propose au Conseil — qui étudie le texte revisé d'un projet de loi relatif à l'établissement de tribunaux - de couper de moitié son traitement de Chancelier et d'Ordinaire, étant donné, disait-il, les frais considérables que les plaideurs doivent supporter. A la même occasion, il accorde le répit de deux mois demandé par le Conseil et fait grâce à tous les esclaves en fuite, espérant par là endiguer le flot des déserteurs et freiner leurs déprédations.

41 De Bouillé, Mémoire Détaillé, AN, Nouv. Acq. Fr., 9430.

42 Mémoire Remis à M. le Marquis de Bouillé par M. de Montdenoix, AN, Colonies $\mathrm{C}^{10} \mathrm{D}^{3}$; De Bouillé au Ministre, 24 février 1779, ANOM, Dessins et Mémoires, Carton II, $\mathrm{n}^{\circ} 134$.

43 Un deuxième Français, Collart D'Auchamps, est nommé en avril 1779 , un troisième Edme Desabaye, en octobre 1779, et un quatrième, John Baptiste Bernard Serrant, en mai 1781. En janvier 1782, un cinquième membre de langue française s'assoyait à la table du Conseil.

44 Dominica, Privy Council Minutes, 14 octobre 1778. 
Cependant, la lune de miel prend fin avec l'arrivée de la nouvelle année. L'amélioration des ouvrages de défense est le principal souci de Duchilleau. Il s'attaque à cette tâche avec diligence et y consacre des sommes considérables. Après avoir fait lui-même une tournée d'inspection, il avait dressé un plan détaillé des défenses nécessaires pour assurer la sécurité de l'île.45 Il constata alors qu'il n'y avait aucun atelier de menuiserie, que les outils manquaient et que la quantité de bois (pieux et madriers) et de fer disponible était nettement insuffisante. ${ }^{46}$ Faisant la sourde oreille aux recommandations de De Bouillé qui lui conseille d'allier l'efficacité à l'économie, il embauche des ingénieurs pour renforcer les fortifications et construire des redans, affecte les militaires à des travaux de défense, leur versant une solde de 40 sous par jour (elle était de 10 sous à la Martinique), mobilise les esclaves noirs et réquisitionne toutes les armes lourdes et les munitions qu'il peut trouver. En outre, il réclame encore plus de soldats afin d'assurer l'entretien des routes et ferme l'hôpital de Roseau pour en ouvrir une nouvelle à Soufrière, où les militaires blessés venant des autres îles françaises pourront prendre des bains chauds. De Bouillé qui reçoit les factures craint pour l'avenir, car il sait que Duchilleau va poursuivre sans relâche l'érection de nouvelles défenses, qu'il va exiger de plus en plus d'hommes et qu'il va continuer à construire des voies d'accès dans toutes les directions. De fait, Duchilleau a même ouvert une route qui relie la côte est à la côte ouest, au travers des marécages de Layou. De Bouillé réprimande le gouverneur, mais sans grand résultat. ${ }^{47}$ Ce dernier s'obstine, disant qu'il vaut mieux dépenser de l'argent que de risquer de perdre la Dominique. Bien plus, il invite le gouverneur général à inspecter les travaux, et De Bouillé se rend visiter l'île en février 1779. Enchanté de ce qu'il a vu, De Bouillé écrit au Ministre de la Marine qu'il a trouvé la Dominique "imprenable" et que les Français et les Anglais vivent tranquilles sous le gouvernement de Duchilleau. ${ }^{48}$ La population française est peut-être calme, mais les Anglais rongent leur

${ }^{45} \mathrm{De}$ Bouillé, Instructions, 15 septembre 1779, ANOM, Dessins et Mémoires, Carton II, $\mathrm{n}^{\circ} 138$.

46 M. Rallier, Mémoire sur les Fortifications de la Dominique, 7 mars 1780 , ibid., n 139.

47 De Bouillé, Mémoire détaillé, Bibl. Nat., Nouv. Acq. Fr., 9430; De Bouillé, Instructions, 15 septembre 1779, Rallier, Mémoire, 7 mars 1780 , ANOM, Dessins et Mémoires, Carton II, nos 138 et 139 ; H. A. A. Nichols, Dominica, with Views of the Island (St. John's, 1905), 12.

48 De Bouillé au Ministre, 24 février 1779, ANOM, Dessins et Mémoires, Carton II, $\mathrm{n}^{\circ} 134$. 
frein car Duchilleau les a tous indisposés avec son programme de défense.

Le premier affrontement se produit le 4 janvier 1779 lorsque Duchilleau renvoie au Conseil deux projets de loi accompagnés d'un message cinglant. Le gouverneur s'indigne de voir qu'en vertu d'un de ces bills, seulement 1/16 des esclaves de l'île est affecté aux travaux publics tandis qu'auparavant la proportion était de $1 / 8$. De plus, il proteste contre le deuxième bill qui oblige les troupes françaises et les fonctionnaires à payer divers impôts comme la taille capitale et les taxes sur la location des maisons, sur les esclaves, sur les habitations et sur les terres. Faisant remarquer que la "réduction" du nombre des esclaves envoyés aux travaux publics témoigne "d'un zèle plutôt tiède pour le service de Sa Majesté", il donne l'avertissement que si cette situation n'est pas corrigée, "l'autorité militaire - à laquelle il est toujours désagréable de faire appel - deviendra ma seule ressource". ${ }^{49} \mathrm{En}$ réalité, il s'était déjà servi de ce moyen lorsqu'il avait ordonné à un conseiller, Abraham Shaw, de prendre, "sous peine d'exécution militaire", les mesures requises pour qu'à 7 heures du matin, le 4 janvier 1779, les esclaves fournis habituellement par quatre paroisses (St. George, St. Patrick, St. Luke et St. Paul) se présentent à Roseau pour accomplir une semaine de travail..$^{50}$ Trois jours plus tard et malgré l'absence de quelques membres, L'Assemblée fait rapidement subir aux deux projets de loi les trois lectures réglementaires. Le Conseil s'empresse de sanctionner les deux bills et les soumet à l'approbation du gouverneur.

Le mois suivant, d'autres frictions se produisent. A la demande de Duchilleau, les législateurs avaient accepté de vendre des bestiaux à un prix raisonnable aux troupes ainsi qu'à l'hôpital. Le contingentement avait été fixé à quatre bœufs par semaine, et un comité formé de membres de l'Assemblée s'était vu imposer la tâche de partager entre les propriétaires de bêtes à cornes la responsabilité de fournir les animaux exigés. ${ }^{51}$ Lorsque le 7 février, seulement 124 livres de viande sont livrées (il en aurait fallu 360 livres, uniquement pour nourrir les soldats hospitalisés), Duchilleau loge des militaires dans la maison d'un membre du Comité de l'Assemblée, à la grande stupéfaction des

49 Dominica, Privy Council Minutes, 4 janvier 1779.

50 Ibid.

51 L'entente initiale prenait fin le $1^{\text {er }}$ décembre 1778 , mais elle fut prolongée jusqu'au mois de février 1779 . 
législateurs. ${ }^{52}$ Ensuite le 12 février, il fait remettre à l'Assemblée une note sévère dont les premiers mots ,"les mesures rigoureuses m'ont toujours répugné", firent sans doute naître un sourire sarcastique chez ceux à qui ils s'adressaient. ${ }^{53}$ Le lendemain, le Conseil et l'Assemblée au grand complet se rendent à la résidence du gouverneur où le président, Alexander Stewart, lit une adresse rédigée en termes respectueux, mais qui dissimule mal le mécontentement des membres. Les législateurs protestent contre le traitement infligé à l'un des leurs et soulignent le fait que les termes de la capitulation n'imposent pas l'obligation d'approvisionner l'hôpital et que, si on le fait, c'est par pur sentiment humanitaire. On propose que chaque habitant soit tenu de déclarer sous serment, en présence du trésorier colonial, le nombre de bêtes à cornes, de moutons et de chèvres qu'il possède, et l'on s'engage à fournir de la viande fraîche aussi longtemps que les ressources de l'île le permettront. Enfin, on assure le gouverneur que le Comité remplira fidèlement son devoir, pleinement confiant que ses membres ne seront ni collectivement, ni individuellement soumis à des contraintes comme celles qui ont été exercées récemment à l'égard de l'un des leurs et qui sont si contraires à l'esprit de ce Gouvernement qui nous a été garanti par les articles de la Capitulation, et particulièrement par l'administration de Votre Excellence dont nous respectons la personne, et auxquels articles nous promettons, quant à nous, de nous conformer rigoureusement. ${ }^{54}$

Duchilleau accepte la formule proposée. Néanmoins, il continue à demander des troupes et, face à l'accroissement de la garnison, il en vient à exiger une bête à cornes par jour. Comme le nombre de bestiaux diminue de façon alarmante, les législateurs offrent une prime de $\$ 4$ par tête de bétail à quiconque importera des animaux. Cette mesure n'obtient pas les résultats espérés, car il ne se fait pratiquement plus d'importations. Tous les planteurs, et en particulier ceux qui cultivent la canne à sucre, tirent le diable par la queue.55 Il leur faut des bêtes de trait

52 En 1795, le gouverneur Hamilton se prépara à cantonner des troupes dans la demeure de Charles Winstone, devant le refus de ce dernier d'envoyer six esclaves aux travaux publics (Hamilton à Portland, 22 juin 1795, PRO, CO 71/27).

53 Dominica, Privy Council Minutes, 12 février 1779. Atwood s'est montré particulièrement amer sur la question du bétail.

54 Dominica, Privy Council Minutes, 13 février 1779.

55 Dominica, Privy Council Minutes, 18 décembre 1779; Winstone à Rae, janvier 1780, (MS), Clements Library, Winstone Letterbook. 
et de l'engrais, deux choses qu'ils ne peuvent manufacturer. De plus, ils ont besoin de lait, aussi bien pour nourrir leurs familles que pour se procurer des revenus. En juillet 1779, au moment où De Bouillé écrit fièrement à un correspondant de France que tous les ouvrages essentiels à la défense de la Dominique sont parachevés, et pendant que Duchilleau porte la garnison à 1519 hommes, Charles Winstone, propriétaire terrien, avocat des planteurs et membre du Conseil, se plaint à Messieurs Langston et Dixon, marchands de Londres, qu'il juge l'état de l'île "des plus pénibles". ${ }^{56}$

Le commerce est dans le marasme. En outre, les échanges commerciaux avec les colonies de l'Amérique continentale ont cessé dès le début de la Révolution américaine, parce que les Britanniques s'emparaient de tous les navires battant pavillon étoilé qu'ils rencontraient. Enfin, l'occupation de la Dominique par les Français a aggravé une situation déjà peu reluisante. Donc, il est défendu de commercer directement avec l'Angleterre et, de plus, un décret français interdit à tout navire venant de France ou de la Nouvelle-Angleterre de faire escale à la Dominique. Le seul moyen qui reste d'atteindre le marché anglais est d'expédier les produits de l'île à Amsterdam ou à d'autres villes neutres d'Europe, via le port libre de St. Eustatius, étant donné que pendant la Guerre de Sept ans l'Angleterre s'attaquait à tous les navires neutres qui arrivaient directement des îles françaises. ${ }^{57}$ Cette route maritime détournée ainsi que le prix élevé du fret ne rapportent guère de bénéfices aux propriétaires antillais et aux marchands de Londres. Cependant, mieux valaient de maigres profits que rien du tout. ${ }^{58} \mathrm{Au}$ début, le gouvernement français voit d'un mauvais œil l'utilisation du port de St. Eustatius et tente d'y mettre un frein, de peur que la Dominique ne serve d'entrepôt de marchandises pour les îles françaises et nuise ainsi au commerce avec la France. Toutefois, De Bouillé et Duchilleau s'opposent avec succès à Versailles. ${ }^{59}$ Les vaisseaux

56 Winstone à Langston et Dixon, 6 juillet 1779, (MS), ibid.

57 Décision prise à une réunion des planteurs de la Dominique tenue le 4 décembre 1778 ( $\mathrm{PRO}, \mathrm{CO} 71 / 7)$.

58 Atwood, op. cit., 155, 160 ; Coke, op. cit., II : 341.

59 De Bouillé au Ministre, 6 janvier 1779, ANOM, Dessins et Mémoires, Carton II, $\mathrm{n}^{\circ}$ 131. Après la guerre, en 1784, De Bouillé fit une visite de cinq mois en Angleterre. Les planteurs et les marchands de Londres et de Glasgow intéressés aux Antilles célébrèrent publiquement son attitude humaine et généreuse; ceux de Londres, Richard Neave inclus, lui présentèrent une épée d'acier et un plateau d'argent; ceux de Glasgow, une paire de pistolets avec inscription. La reine Charlotte, lors d'une réception officielle, lui fit cette remarque: "Monsieur le marquis, il faut que vous ayez 
dominicains sont donc autorisés à prendre leurs cargaisons à St. Eustatius et à se rendre à Amsterdam où Hope and Company se charge d'acheminer les marchandises vers l'Angleterre. A Rotterdam, c'est la maison Cranfurd and Company qui assure le transit. Néanmoins, l'aventure est périlleuse, car les vaisseaux de guerre britanniques et les flibustiers, non contents d'intercepter chaque navire dominicain en route pour St. Eustatius sous prétexte que les produits de l'île sont français, confisquent leurs chargements "sans aucun scrupule".60 C'est alors qu'un comité, ayant à sa tête Richard Neave et formé de propriétaires dominicains résidant en Angleterre, imagine un plan qui permettra d'utiliser les bâtiments hollandais. Les conseillers juridiques de la Couronne, Wynne, Wedderburn et Wallace, soutiennent que les habitants de la Dominique ne sont tenus qu'à une stricte neutralité, qu'ils ne sont pas sujets français, que leurs biens ne sont pas français et que l'on ne peut confisquer ni les marchandises qu'ils exportent à bord de navires neutres, ni les navires eux-mêmes. ${ }^{61}$ En conséquence, l'Angleterre reconnaît aux vaisseaux hollandais le droit de transporter les produits de la Dominique. Cependant, la joie des Dominicains à l'annonce de cette nouvelle est de courte durée. Le premier navire à faire escale à l'île n'arrive qu'en novembre 1779 et, peu de temps après, ils apprennent avec découragement qu'un juge amiral de SaintChristophe a saisi un bâtiment hollandais qui transportait une cargaison en provenance du district dominicain de Rosalie. ${ }^{62}$

La pénurie des importations et des exportations, la hausse considérable du prix des denrées qui oblige les planteurs à donner à leurs esclaves du sel au lieu des viandes salées qui coûtent trop cher (ils les encouragent à consommer des produits de l'île comme le porc et les grenouilles), le manque de main-d'œuvre agricole causé par l'absence des esclaves mobilisés pour les travaux publics, l'obligation d'approvisionner les troupes en bétail, la baisse du prix du café (le seul produit de l'île qui soit en demande et qui ne se vend que sept ou huit sous la livre), toutes ces difficultés incitent les Anglais à quitter l'île, du moins

bien du mérite pour vous faire tant aimer de ceux dont vous vous étiez fait si longtemps craindre."

60 Winstone à Langston et Dixon, 6 juillet 1779, Clements Library, Winstone Letterbook.

61 Great Britain, Privy Council, Acts (London, 1908-1912), V: 592.

62 Winstone à Stuart, 12 janvier 1780, et Winstone à Senior, 13 janvier 1780, Clements Library, Winstone Letterbook; Germain à Knox, 31 mars 1779, dans Great Britain, Historical Manuscripts Commission, Report, Variows Collections, VI: 157. 
ceux qui sont en mesure de le faire et qui réussissent à obtenir une autorisation écrite du gouverneur. ${ }^{63}$ Cet exode va encore s'accentuer à la suite d'une rumeur persistante qui veut que la Dominique soit cédée à la France à la fin de la guerre, et aussi à cause d'une décision du gouvernement français. En effet, les autorités ont décidé que les affermataires sont tenus de payer le rachat des corvées ("quit-rents"), ainsi que les arrérages de cette redevance. ${ }^{64}$ Les législateurs, prétendant que l'Angleterre n'avait pas perçu ces droits pendant un bon nombre d'années avant la chute de l'île, et invoquant l'extrême pauvreté des habitants, demandent la suspension des paiements. De Bouillé et Montdenoix répliquent par une longue lettre datée du 13 avril 1779. Ils font observer que toutes les colonies se ressentent durement des conséquences de la guerre, qu'un bon nombre de Dominicains possèdent sans aucun doute l'argent nécessaire pour acquitter cette dette, puisqu'ils ont refusé d'attendre la signature du traité de paix pour payer ce qu'ils doivent à l'Europe, et que, de toute façon, la somme due n'est que de 180,000 livres, y compris les arrérages. ${ }^{65}$ Ils ajoutent avec une pointe d'aigreur "que dans une colonie où la population anglaise est quatre fois plus nombreuse que la population française, une quarantaine de Français ont déjà commencé à payer le rachat des corvées, tandis que deux Anglais seulement paraissent avoir fait des versements". Et la lettre se termine par une mise en demeure d'avoir à payer sans délai. ${ }^{66}$

Toutefois, à la suite d'un ouragan qui dévasta la Dominique et la Martinique les 29 et 30 août, la perception du rachat des corvées fut suspendue provisoirement. ${ }^{67}$ Les moissons furent en-

${ }^{63}$ Winstone à Langston et Dixon, 6 juillet 1779, Clements Library, Winstone Letterbook.

${ }^{64}$ Les cinq ans d'arrérages de la propriété Vernedes de 152 acres à 2 s. sterling l'acre, s'élevaient à 76 livres sterling. Le cours du change étant de $182 \frac{1}{2}$, ceci représentait la jolie somme de $£ 134.14 \mathrm{~s}$ (Winstone à Langston et Dixon, 6 juillet 1779 , ibid.).

es En 1780, la Dominique devait à l'Angleterre 1,500,000 livres sterling (Great Britain, Privy Council, Acts, V : 592).

66 Dominica, Privy Council Minutes, 18 mai 1779. Dans les cas où "on le demandait comme une faveur", les intérêts sur les arrérages furent annulés.

${ }^{67}$ De Bouillé et De Peinier au Ministre, 6 octobre 1780, AN, Colonies $C^{8}$ A 79. Le recouvrement de cette redevance fut encore une fois interrompu après la tornade de 1780 . Il allait redevenir en vigueur sauf, semble-t-il, pour une brève période consécutive à l'incendie de Roseau en 1781. Lorsqu'ils quittèrent la Dominique en 1784 , les Français n'avaient pas réussi à collecter intégralement la redevance due au 4 mars 1783 , non plus que les dettes contractées par les planteurs qui avaient acheté à crédit, pendant 
tièrement détruites, les plantations de canne à sucre et de caféiers subirent des dégâts considérables et plusieurs bâtiments furent démolis. Les dommages matériels s'élevèrent à plus de 100,000 livres. ${ }^{68}$ Le prix des denrées dégringola : le prix du café baissa à 5 soles la livre, celui du sucre à $16 / 6$ le cent livres, et le rhum à 2 shillings le gallon. Pendant ce temps, le coût des produits importés grimpait en flèche : le prix du bœuf passa de $£ 9.18 .0$ à 111 le baril ; celui du beurre, de £9.18.0 à £13.4.0 le tonnelet; et le poisson salé finit par se vendre £5 le cent livres. Le beurre et le poisson étaient les deux aliments les plus difficiles à trouver. ${ }^{69}$ Les îles voisines ne disposaient elles-mêmes que de peu de vivres, et De Bouillé, qui avait envoyé ce qu'il pouvait de la Martinique (éprouvée elle aussi par le cataclysme), se tourna du côté de l'Europe et de l'Amérique du Nord. ${ }^{70}$ Quant à Duchilleau, il renonça généreusement à ses émoluments de Chancelier et d'Ordinaire, ainsi qu'aux revenus que procurait la taxe sur "les tenanciers de tavernes et de salles de billard". ${ }^{71}$ Il imposa cependant des droits d'entrée sur les exportations, poursuivit la construction d'ouvrages de défense et insista pour que les habitants continuent à fournir des esclaves et du bétail. Il conseilla toutefois d'importer des animaux du continent.

En janvier 1780, un bon nombre de résidents anglais des Blancs et des gens de couleur - ont quitté la Dominique et ceux qui restent font face "à la ruine et à la misère". Les

les moments difficiles, des marchandises provenant des magasins du Roi. A la suite d'un accord signé le 1 er janvier 1784 par Alexander Stewart et Charles de Lorme (intendant intérimaire de la Dominique), un percepteur français fut laissé sur l'île afin de recueillir les arrérages. Le gouverneur général De Damas et le gouverneur John Orde acceptèrent qu'une commission se rende à la Dominique afin d'étudier la question. Il était de notoriété publique qu'un dénommé Kendrick, qui devait des arrérages, avait été amené dans une prison de la Martinique par ordre de De Beaupré, gouverneur de la Dominique, et qu'il n'avait été libéré qu'après avoir promis de payer sa dette, promesse que d'ailleurs il ne tint pas. En juin 1785, M. Arbonne, nommé percepteur par le gouverneur général et l'intendant, arrivait à la Dominique. Orde refusa de le recevoir et demanda conseil à lord Sydney, secrétaire anglais aux colonies. Sydney soumit l'affaire au Ministre français "pour un règlement à l'amiable" (Sydney à Orde, 6 mai 1784, PRO, CO 71/8; Sydney à Orde, 4 août 1785, PRO, CO 71/2; De Damas au Ministre, 26 janvier 1784, AN, Colonies C8 A 84).

68 Dominica, Privy Council Minutes, 3 septembre 1779; Winstone à Dickinson, 12 septembre 1779, Clements Library, Winstone Letterbook. 156-157.

69 Winstone à Chollet, 18 janvier 1779 [1780], ibid.; Atwood, op. cit.,

70 De Bouillé, Mémoire Détaillé, Bibl. Nat., Nouv. Acq. Fr., 9430.

71 Dominica, Privy Council Minutes, 2 septembre 1779. 
législateurs envoient alors à la Martinique un membre de l'Assemblée, John Gillon, demander une réduction des droits de douane sur les exportations, ainsi que la permission d'importer du bétail de l'Espagne, soit par le truchement d'un armateur indépendant, soit par contrat, soit par l'intermédiaire d'un vaisseau équipé aux frais du gouvernement français. ${ }^{72}$ Les autorités de la Martinique se rendent à la première demande et il y a tout lieu de croire que la deuxième sera aussi accordée, puisque Gillon, lui-même, avance l'argent nécessaire pour armer un navire espagnol. Malheureusement, on refuse à Cadix d'honorer sa traite..$^{73} \mathrm{M}$. Bellot, désigné en avril 1779 pour représenter la colonie auprès de la cour de Versailles, obtient encore moins de succès au cours d'un voyage à Paris. En mai 1780, en réponse à sa demande de suspendre la perception du rachat des corvées, on lui conseille de s'adresser d'abord aux administrateurs de la Martinique. ${ }^{74}$

En dépit de cette série d'infortunes, la vie continue à la Dominique. La loi qui autorise et qui taxe "les tavernes, les débits de boissons et les salles de billard, etc.", est toujours renouvelée et se révèle opportune, quand ce ne serait que pour la présence des militaires qui constituent une clientèle assurée bien que parfois un peu bruyante. ${ }^{75}$ En mai 1780, Mary Greg avait ouvert, dans le village éloigné de Portsmouth, une taverne où elle logeait aussi les voyageurs. On sait qu'elle fut dispensée de payer le permis annuel de $£ 50$, mais on ne connaît pas son chiffre d'affaires. ${ }^{76}$

72 Winstone à Stuart et Winstone à Chollet, 12 et 18 janvier 1780 , Clements Library, Winstone Letterbook. Ils demandaient aussi d'être dispensés du rachat des corvées et que les tenures à bail soient converties en propriétés libres. Ils ajoutaient que cette dernière mesure avait déjà été adoptée par les Anglais avant la capture de l'île. Malgré l'opposition de De Bouillé, la France se montra disposée à acquiescer à leur requête. Cependant, une fois la conversion autorisée, la population anglaise, maintenant convaincue que l'île serait remise à la Grande-Bretagne à la fin du conflit, se désintéressa de la question (Dominica, Privy Council Minutes, 3 septembre 1779; Johnstone à King, 9 octobre 1799, PRO, CO 71/2). $C^{8}$ A 80.

73 De Bouillé et De Peinier au Ministre, 18 avril 1781, AN, Colonies

74 Dominica, Privy Council Minutes, 6 avril 1779; Mémorandum, 30 mai 1780, AN, Colonies $\mathrm{C}^{8} \mathrm{~B}$ 15; De Bouillé et De Peinier au Ministre, 6 octobre 1780, AN, Colonies C8 A 79 .

75 Dominica, Privy Council Minutes, 16 octobre et 21 octobre 1778, 19 novembre et 3 décembre 1779; Atwood, op. cit., 151 .

76 Dominica, Privy Council Minutes, 5 juin 1780. Le 27 février 1779, Hester Barnett, tavernier à Roseau, avait été exempté du paiement de ce permis pour une période de trois mois. 
Loin d'apporter un soulagement, l'année 1779 allait être témoin d'autres adversités. Douze cents hommes malades appartenant à une flotte espagnole (l'Espagne était devenue l'alliée de la France par suite de sa déclaration de guerre à la GrandeBretagne en 1779) débarquent à la Dominique. Ce sont de nouvelles bouches à nourrir. Le 30 septembre, la mer s'élève subitement à vingt et un pieds au-dessus de son niveau normal endommageant des habitations et des navires. Ensuite, un incendie éclate à Roseau. Puis, le 11 octobre, l'un des pires ouragans de l'histoire de la colonie provoque un raz de marée. Par un vent violent et sous une pluie diluvienne, la vague de fond entraîne dans la mer les maisons construites sur la côte et cause de lourds dégâts aux fortifications. ${ }^{77}$ De toutes les provisions entreposées dans les magasins du Roi, on ne réussit à sauver que 175 barils de farine. Puisque la plus grande partie de cette denrée devait servir à l'approvisionnement des troupes, les autorités ne purent distribuer à la population toute la farine qu'elles auraient voulu lui donner. ${ }^{78}$

Il ne faut donc pas s'étonner de voir les Anglais - et parmi eux le juge en chef Thomas Wilson - continuer à déserter l'île. A la suite de cette émigration massive, la population de la Dominique baissa, en l'espace de deux ans, à 1,066 Blancs (dont les trois quarts étaient Français), 543 Noirs affranchis et 12,713 esclaves. ${ }^{78}$

77 De Bouillé et De Peinier au Ministre, 29 octobre 1780, AN, Colonies C8 A 79; De Bouillé à Monseigmeur, 1er novembre 1781, Archives du Ministère de la Guerre, Vincennes, Série $A^{4}$, Carton XLIXa; Winstone à Chollet, 6 juillet 1781, Clements Library, Winstone Letterbook. Selon Great Britain, Report of the Royal Commission to Inquire into the Condition and Affairs of the Island of Dominica (London, 1894), x, C. 7477, les deux désastres seraient survenus en 1781 . Des sommes d'argent, recueillies bénévolement en Angleterre afin d'aider les sinistrés, arrivèrent si tard à destination que l'on s'en servit pour bâtir une prison en 1785 (Ibid.; Atwood, op. cit., 185).

${ }^{78}$ De Peinier au Ministre, 8 avril 1781, AN, Colonies C8 A 80.

79 Bayley, op. cit., 653. Charles Winstone qui songeait à déménager à Saint-Christophe fit un voyage d'affaires de plusieurs semaines à Antigua et revint à la Dominique en novembre 1780. Au printemps de 1781 , il s'installa à Saint-Christophe pour revenir encore une fois à la Dominique au mois de mai. Selon toute apparence, il ne s'était pas plu à St. Kitts (ou Saint-Christophe). A la fin de septembre 1781, persuadé que la Dominique allait demeurer colonie française, il partit pour Antigua en qualité de solliciteur général, avec l'intention de ne plus revenir. Cependant, en 1783 , assuré de la permanence du régime anglais, il revint pour de bon à la Dominique ("Matson Letters Relating to Dominica, 1800-1805", Caribbeana, I: 220; Winstone à Greg, 5 décembre 1781, Clements Library, Winstone Letterbook). 
Le départ de Duchilleau en juillet dut faire naître chez plusieurs l'espoir secret qu'il ne reviendrait pas. Hélas, son remplaçant, le vicomte de Damas, ne resta en fonction que quelques mois. En novembre, Duchilleau était de retour et imposait de nouveau le règlement impopulaire qui obligeait les Dominicains à fournir des esclaves pour les corvées. ${ }^{80}$

Les relations du gouverneur avec le Conseil et l'Assemblée demeurent tout aussi tendues, bien que les législateurs soient reconnaissants à Duchilleau d'avoir renoncé aux émoluments de sa charge ainsi qu'à son traitement de $£ 12,000$ pour secourir les sinistrés. ${ }^{81}$ Dans une pétition relative au désastre, pétition que Duchilleau ne modifie en rien malgré son goût prononcé pour la censure, les législateurs qualifient la politique du gouverneur en matière de bétail de "mesure qui a déjà causé beaucoup de tort aux planteurs". ${ }^{82}$

Les rapports entre le gouverneur et les administrateurs s'enveniment de plus en plus. Les Anglais reprochent à Duchilleau de traiter sur le même pied que les autres Dominicains les gens libres de couleurs (d'origine française pour la plupart) et de prodiguer trop d'éloges à leur milice; ils s'indignent des propos cavaliers que le gouverneur et ses officiers tiennent aux femmes anglaises, propos offensants pour les oreilles de ces dames; ils protestent contre la conduite d'un Noir français affranchi qui a giflé le juge en chef, un de leurs compatriotes; enfin, ils trouvent inadmissible l'impudence d'un certain Etienne Vring qui, dans une taverne, a osé menacer de son épée "un respectable marchand anglais". 83 En outre, les Anglais protestants voient

80 Parmi les autres difficultés que le gouverneur eut à affronter, il y avait les poursuites judiciaires entreprises par Jacob de Kempenaer et John van den Kerkhoff, deux citoyens de La Haye, contre Olivier Nugent, propriétaire de la Dominique qui devait aux demandeurs une somme considérable (Observations sur la Conduite de M. Nugent soumises à la Considération de Son Excellence le Marquis Duchilleau, 28 novembre 1780, (MS), Bibliothèque de la Marine, Brest, Manuscrit no 35 ; De Peinier au Ministre, 21 juillet 1781, AN, Colonies C8 A 80).

81 Dominica, Privy Council Minutes, 2 septembre 1779 et 15 février 1781. Comme l'on pouvait s'y attendre, Atwood passe sous silence ce geste généreux de Duchilleau.

82 Dominica, Privy Council Minutes, 15 février 1781.

83 Atwood, op. cit., 151-152. Duchilleau se montrait enthousiaste à l'égard des gens de couleur qui appartenaient à la Milice, mais plutôt tiède envers les Blancs (De Bouillé au Ministre, 29 septembre 1781, AN, Colonies C8 A 80). Aussi, les Anglais de race blanche de la Dominique pouvaient difficilement se réjouir lorsqu'ils apprirent que le gouverneur avait reçu, le 30 août 1782, l'autorisation de mettre sur pied dans les Antilles une 
avec déplaisir l'arrivée de missionnaires français (des Franciscains et des Capucins) et de plusieurs prêtres séculiers qui s'installent dans les paroisses situées sur la côte Sous-le-vent, ainsi que dans l'ancienne habitation des Jésuites à Grande Baie. Parmi les nouveaux venus, se trouve un Antillais de naissance, Jean-Baptiste Romefort. Après avoir servi dans l'ordre des Dominicains en France, Romefort était venu exercer son ministère à Colihaut en 1778 , en qualité de prêtre séculier. ${ }^{84}$ Donc, les occasions de blâmer Duchilleau, l'incarnation vivante de la domination française, se multiplient de jour en jour, d'autant plus que la situation économique de l'île ne cesse de se détériorer.

En Angleterre, le Parlement et le Conseil privé font l'impossible pour venir en aide à leurs anciens sujets. Le 29 décembre 1780, le Conseil privé, appliquant une loi votée par le Parlement, ordonne que les vaisseaux hollandais, porteurs de produits de la Dominique, de Saint-Vincent, de la Grenade et des Grenadines, soient considérés comme navires neutres et qu'on les laisse entrer dans n'importe quel port de la Hollande sans les confisquer. ${ }^{85}$ Cependant, la déclaration de guerre des Pays-Bas à l'Angleterre, suivie de la capture de St. Eustatius par l'amiral George Rodney, vient encore une fois faire surgir le problème du transport maritime dans toute son acuité. Quelques planteurs réussissent à expédier leur sucre à Ostende à bord de bâtiments battant pavillon britannique. Toutefois, ils n'obtiennent que £6 à £8 le tonneau, prix ridiculement bas si on le compare aux $£ 15$ ou aux $£ 16$ payées auparavant à Rotterdam. ${ }^{86}$

$\mathrm{Au}$ cours de 1781, les administrateurs aussi bien que les législateurs deviennent exaspérés. En février, une décision de Duchilleau donne lieu à une querelle acerbe. Le gouverneur refuse de sanctionner le renouvellement de l'Acte juridique aussi longtemps que les législateurs ne prolongeront pas, pour un même laps de temps, une loi de 1780 qui oblige les créanciers à accepter les produits de leurs débiteurs et qu'ils ne modifieront pas ladite loi de façon à mieux protéger ces derniers. ${ }^{87}$ Devant l'attitude

force composée exclusivement de gens libres de couleur. Ils ne pouvaient pas prévoir qu'en 1795 la Grande-Bretagne allait sanctionner la création d'un régiment de Noirs destiné à servir aux Antilles.

84 Jean Raymond de Boisgelin, 12 avril 1776, J. Margaux, 13 juin 1778, AN, Colonies F3 44 .

85 Great Britain, Privy Council, Acts, V: 488.

86 Atwood, op. cit., 155-156; Coke, op. cit., II: 342.

87 L'Acte juridique du 13 février 1781 prévoyait l'établissement de tribunaux d'actions civiles, de revision, du Banc du Roi, des sessions extra- 
du gouverneur, le Conseil introduit une clause qui empêche le grand prévôt de réquisitionner "les esclaves, les chevaux, les mules et les bestiaux", ainsi que les instruments aratoires des planteurs. Il ne reste donc plus que les produits de la terre qui peuvent être saisis. Ceux qui n'ont pas de plantations et qui, par conséquent, ne disposent d'aucune denrée de consommation doivent céder d'autres choses que des produits agricoles ou des esclaves. Toutefois, ces derniers peuvent être mis au travail afin de satisfaire les créanciers. L'Assemblée rejette cette clause à l'unanimité, soutenant que la loi "est déjà envers les débiteurs d'une indulgence sans précédent", qu'un bon nombre de ces derniers ne produisent rien et que plusieurs d'entre eux pourraient être tentés de faire de l'argent en occupant les Noirs à des travaux autres que ceux de la terre pour échapper à leurs créanciers. ${ }^{88}$ Le Conseil propose alors à l'Assemblée d'autres amendements destinés à protéger les débiteurs qui se sont vu enlever sans pitié leurs esclaves et leurs bestiaux. Mais l'Assemblée ne veut pas démordre, et le projet de loi dont on se contente de prolonger la durée est adopté par les deux Chambres le 3 avril. Duchilleau peut quand même se flatter d'avoir remporté une demi-victoire.

En réalité, ce qui avait indisposé les législateurs était un message de Duchilleau qui demandait de reviser la première clause de la Loi sur les Actes publics de façon que tous les documents (y compris les contrats et les actes de cession ou de transfert) écrits en français soient tout aussi valides que ceux qui étaient rédigés en langue anglaise. ${ }^{89}$ Et Duchilleau insistait sur le fait que la loi initiale ne pouvait pas être maintenue, parce que la Dominique comptait plus de Français que d'Anglais et que l'île était une possession française. En conséquence, ajoutait-il, Thomas Chabaud Arnault, nommé notaire royal, est chargé de consigner tous les documents par écrit. Les législateurs furent sans doute piqués au vif de s'entendre dire sans ménagement qu'ils étaient sous la domination de la France et d'apprendre qu'ils auraient à endurer cet Arnault qu'ils détestaient cordialement en raison de son activité dans la cinquième colonne. Les membres des deux Chambres rédigèrent "une pro-

ordinaires, etc. Plusieurs marchands de Roseau avaient présenté une requête contre la loi initiale sur les créanciers, mais la loi fut quand même adoptée le 7 juin 1780 (Dominica, Privy Council Minutes, 7 juin 1780 et 23 février 1781).

88 Dominica, Privy Council Minutes, 20 mars et 21 mars 1781.

$89 \mathrm{La}$ validité des testaments était déjà reconnue, quelle que fût la langue dans laquelle ils étaient faits. 
testation respectueuse" mais apparemment très ferme puisqu'on n'a pas jugé bon de la rapporter - pas plus d'ailleurs que la réponse de Duchilleau - dans le registre des procès-verbaux du Conseil. ${ }^{90}$ Le firmament politique était encore très sombre quand le malheur s'abattit de nouveau sur la Dominique.

Le 16 avril 1781, le soir du dimanche de Pâques, un incendie se déclara à Roseau. En moins de quelques heures, le feu rasa près de 600 maisons, $\mathrm{y}$ compris les principaux édifices et les magasins, causant des dommages évalués à plus de $£ 200,000$. Cette troisième calamité en autant d'années terrassa littéralement la population. Plusieurs résidents anglais soupçonnèrent fortement que Duchilleau lui-même avait donné aux soldats français ou à un agent secret l'ordre de mettre le feu, surtout qu'il avait déjà menacé de brûler la ville.91 Ces soupçons se transformèrent en quasi certitude quand le gouverneur fit son apparition dans les rues de la ville pendant le sinistre et que, selon certains, il ordonna à la troupe de n'aider que les résidents français à sauver leurs biens. En outre, les Anglais furent indignés de voir plusieurs soldats profiter de la situation pour piller les débits de boissons et s'enivrer. Même qu'un Français, nommé Puncheon, qui s'était emparé d'une barrique de vin de Madère appartenant à John Tilestone, un tavernier, fut poursuivi en justice par sa victime. ${ }^{22}$

Le mois suivant, Duchilleau, qui ne pouvait rester indifférent devant l'animosité croissante dont il était l'objet, quitta la Dominique pour un certain temps. ${ }^{93}$ Il fut remplacé par le baron de Fagan. Duchilleau reprit son poste peu de temps après, mais tomba malade. En août, il demanda la permission de résigner ses fonctions et il rentra en France avec son régiment. De Bouillé ne savait trop par qui le remplacer, car bien que l'ancien gouverneur se fût montré impétueux et que les deux hommes aient eu des vues diamétralement opposées sur des questions d'ordre militaire, Duchilleau s'était révélé "très bon gouverneur dans une colonie aussi importante que la Dominique". ${ }^{44}$

${ }^{90}$ Dominica, Privy Council Minutes, 20 mars, 27 mars et 28 mars 1781.

91 D'après Atwood (op. cit., 151), Duchilleau était l'incendiaire. Coke (op. cit., 341) partage aussi cette opinion, bien qu'il déclare ne pas pouvoir fournir la preuve de la culpabilité du gouverneur.

92 Atwood, op. cit., 150.

93 Il participa à la conquête de Tobago par la France, réussie le $1^{\mathrm{er}}$ juin 1781 (J.-C. Nardin, "Tobago, Antille française (1781-1793)", Annales des Antilles, no 14, 1966: 21).

94 De Bouillé au Ministre, 29 août et 12 septembre 1781, AN, Colonies C8 A 80. En 1782, Duchilleau revint aux Antilles où il participa 
En septembre 1781, De Bouillé choisit le comte de Bourgon, lieutenant de Fort Royal à la Martinique. Cependant, des affaires de famille sur le continent obligèrent Bourgon à se départir de sa charge. Il fut remplacé par De Beaupré. ${ }^{95}$

L'état pitoyable de l'île après l'incendie de Roseau incita De Bouillé et l'intendant Peinier à envoyer, de la Martinique, des vivres et $d u$ bois de construction. A la suite d'une requête du Conseil et de l'Assemblée de la Dominique et sur les conseils des administrateurs français, les deux officiers publièrent le 24 juillet 1781 une ordonnance qui supprimait les droits de douane et qui devait rester en vigueur pendant au moins deux ans. Ainsi, les caisses de l'Etat cessaient de recevoir le droit de $1 \%$ imposé localement sur les importations et les exportations. De plus, les taxes de $3 \%$ et de $8 \%$ sur les "gros sirops" et le rhum, exportés directement de Roseau à bord de navires américains qui ramenaient du bois d'œuvre se trouvaient également supprimées. Les planteurs dont la maison ou l'entrepôt avait été détruit par l'incendie étaient aussi dispensés du rachat des corvées. ${ }^{96}$

Le commerce à la Dominique ne s'améliora pas sensiblement, même après que De Bouillé se fut emparé de St. Eustatius en novembre 1781. Et puis, pour empirer la situation, des corsaires américains se saisirent en 1781 de deux navires lourdement chargés: le Résolution, parti d'Amsterdam pour la Domi-

à la capture de Saint-Christophe. Bien qu'il ne remit jamais les pieds à la Dominique, on avait en France une haute opinion de ses connaissances sur l'île. Il fut l'un de ceux que Vergennes, ministre aux Affaires étrangères, consulta en décembre 1782 lorsqu'il fut question de remettre la Dominique à la Grande-Bretagne (De Bouillé à Monsieur, 19 février 1782, Archives du Ministère de la Guerre, Série $\mathrm{A}^{4}$, Carton XLIXa; Vergennes à Rayneval, 20 décembre 1782, Archives du Ministère des Affaires étrangères, Paris, Correspondance Politique, Angleterre, volume 539).

95 De Damas au Ministre, 24 novembre 1782, AN, Colonies C8 A 81. Selon Atwood (op. cit., 154), Bourgon aurait été limogé parce qu'il était trop indulgent à l'égard des Anglais ! Avant De Beaupré qui arriva à la Dominique en janvier 1782 (Dominica, Privy Council Minutes, 22 janvier 1782), le comte de Bouillé, neveu du célèbre gouverneur général, et Blanchelande occupèrent successivement le poste de gouverneur de la Dominique. 96 De Bouillé et De Peinier au Ministre, 18 avril et 24 juillet 1781 , AN, Colonies $C^{8}$ A 80. Toutefois, il fallait payer les droits de la Couronne sur tous les produits provenant des îles françaises et destinés à l'exportation. En conséquence, lorsqu'un décret porta cet impôt de 8 à 10 sous la livre en août 1781, le ministre français stipula que les Dominicains étaient tenus, eux aussi, à payer la surtaxe de 2 sous (Mémoire $\mathrm{n}^{\circ} 1,208$ et Mémoire $\mathrm{n}^{\circ} 4,030, \mathrm{AN}$, Colonies $\mathrm{C}^{8} \mathrm{~A}$ 81; le Ministre à De Joubert et De Peinier, 28 juin 1782, AN, Colonies F3 44). 
nique et qui fut confisqué et vendu à Philadelphie, et le brick Erstend, en route pour Ostende avec des produits des plantations, qui fut amené à Boston. ${ }^{97}$ Les planteurs, durement touchés par la saisie et la vente de ces bâtiments et de leurs cargaisons, ne pouvaient que se lamenter. ${ }^{98}$

Cependant, un événement d'un autre ordre devait apporter quelque consolation aux Dominicains. En effet, on était parvenu à ralentir l'activité des maraudeurs noirs qui menaçaient depuis longtemps leur personne et leurs biens. Ces fugitifs, dont la plupart avaient déserté leurs maîtres anglais et qui s'étaient réfugiés dans les régions inhospitalières de l'intérieur, étaient devenus encore plus audacieux après la conquête de l'île par la France. Armés de mousquets, de baïonnettes, de pistolets et de sabres, ils descendaient de leurs repères fortifiés dans les montagnes et s'attaquaient aux plantations. Ils s'emparaient des provisions et du bétail, incitaient les esclaves à les suivre et envoyaient des lettres de menace aux planteurs. Craignant pour leur sécurité, plusieurs habitants de Roseau abandonnèrent leurs plantations et quittèrent même la Dominique. Sur l'étendue de cinq milles qui sépare Roseau de Mahaut, plus au nord, ces hors-la-loi allaient jusqu'à s'attaquer aux voyageurs en plein jour. En 1781, ils assassinèrent dans sa demeure un planteur du nom de Robert Grahame, malgré les supplications de ce dernier "de lui laisser la vie sauve et de prendre plutôt ses biens". Les résidents anglais furent horrifiés à la nouvelle de ce meurtre, surtout William Atkinson, voisin et ami de Grahame. ${ }^{99}$ Ils demandèrent des armes afin de se défendre, mais Duchilleau refusa. Le gouverneur se rendit toutefois aux appels des législateurs et envoya des troupes dans la région. ${ }^{100}$ Quelques marau-

97 C'est en vain que De Bouillé protesta contre cet acte d'aggression auprès du Chevalier de la Luzerne, ministre plénipotentiaire de la France en Amérique (Dominica, Privy Council Minutes, 22 janvier 1782).

98 Atwood, op. cit., 156.

99 Atwood, op. cit., 229; Atkinson à Lowdon, 9 février 1782, (MS), British Museum, London, Egerton MSS 2,612; Dominica, Privy Council Minutes, $1^{\text {er }}$ juin 1781.

100 Atwood (op. cit., 145, 238) soutient que Duchilleau fournissait des armes aux pillards, les encourageait à continuer leurs incursions et qu'il avait même signé avec eux "un pacte d'entraide". Pourtant, dans un message daté du 14 septembre 1778 et adressé à la législature, Duchilleau déclare expressément: "Messieurs, il y a ici des noirs armés; j'en ai vu moi-même. Il est donc indispensable pour votre sécurité et celle de la population qu'aucun noir ne soit autorisé à porter des armes." Cependant, les auteurs anglais n'en continuèrent pas moins à le blâmer sévèrement. Sir Robert Hamilton, commissaire royal en 1893, affirme que "le commandant français 
deurs furent capturés et promptement exécutés. Toutefois, en 1782, William Atkinson déplorait le fait que "cette punition exemplaire n'avait jusqu'ici produit aucun effet sur les autres pillards". ${ }^{101}$

Sous l'administration des successeurs de Duchilleau et après avoir obtenu des fusils pour se défendre, les planteurs et d'autres habitants souscrivirent une somme de 500 "johannes" afin d'anéantir les fugitifs. John Tombs, un planteur, réussit à capturer quelques maraudeurs venus pour le voler. Craignant les représailles de ceux qui s'étaient échappés, il envoya dans les bois, en mission d'espionnage, un de ses Noirs les plus fidèles. Feignant d'avoir été maltraité par son maître, l'esclave gagna la confiance de ses hôtes et apprit qu'ils préparaient une autre attaque contre la plantation. Il s'empressa d'avertir son maître qui distribua des armes à ses esclaves et organisa la défense de sa propriété. Vers minuit, à l'approche des hors-la-loi, les défenseurs ouvrirent le feu, en tuant et en blessant un bon nombre. Les autres battirent en retraite sous le couvert de l'obscurité, emportant leurs morts et leurs blessés. A partir de ce moment et jusqu'à la fin de l'occupation française, les maraudeurs allaient se tenir relativement tranquilles.102

Le 12 avril 1782, l'angoisse étreint tous les cœurs. Dans le détroit qui sépare la Dominique des petites îles connues sous le nom de "Les Saintes", et à la vue de nombreux Dominicains, l'amiral Rodney avec une flotte de 36 vaisseaux engage le combat contre une force navale française de 30 bâtiments. Six navires français sont coulés ou capturés, dont le Ville de Marie, vaisseau de l'amiral De Grasse qui se trouvait à bord..$^{103}$ Un peu

encourageait les fugitifs à tourmenter, à dépouiller et même à assassiner les Anglais" (Great Britain, Report of the Royal Commission, 1894, xii). 101 Atkinson à Lowdon, 9 février 1782, British Museum, Egerton MSS 2,612.

102 Atwood, op. cit., 233-236.

103 French E. Chadwick ed., The Graves Papers and Other Documents Relating to the Naval Operations of the Yorktown Campaign (New York, 1916), 247. J.H. Parry et P.M. Sherlock rapportent que les pertes françaises furent de sept navires, tandis que selon Alan Burns (History of the British West Indies (London, 1965), 530) les Français auraient perdu cinq de leurs bâtiments. La "brèche" présumément pratiquée par Rodney tient plus de la légende que de la réalité. En effet, il n'y avait aucune ligne à enfoncer puisque les navires français étaient éparpillés (Chadwick, op. cit., 247-248). Un des plus gros vaisseaux français fut presque réduit en pièces et alla s'échouer à un endroit qui porte encore aujourd'hui à la Dominique le nom de Rodney's Rock. 
plus tard, l'amiral Samuel Hood arrive sur les lieux et capture quatre autres unités ennemies. La défaite des Saintes, appelée la bataille de la Dominique par les Français, mettait un terme à la puissance navale de la France dans les Antilles. ${ }^{104}$ Elle faisait aussi naître un espoir de paix. De fait, on entama des pourparlers avant que l'année ne s'achève.

Dès le début du mois d'août, l'amiral De Grasse, qui a été fait prisonnier sur parole et qui s'est arrêté à Londres avant de se rendre à Paris, annonce à lord Shelburne que la France a l'intention de garder la Dominique (et Sainte-Lucie). Un peu plus tard, Alleyne Fitzherbert, envoyé dans la capitale française par le gouvernement anglais, confirme les propos de De Grasse. En septembre, Shelburne se montre disposé à accepter les réclamations de la France, mais refuse de céder à la fois la Dominique et Sainte-Lucie. Il propose que les Français conservent plutôt la Dominique et la Guadeloupe, ou Sainte-Lucie et la Martinique (Georges III préférait cette dernière solution). Le 3 septembre, au cours de débats orageux, le gouvernement britannique maintient son attitude et exige le retour de la Dominique. A Versailles, Vergennes hésite, car il sait très bien que ses compatriotes des Antilles tiennent à conserver cette colonie. Pourtant, avant la fin du mois, il accepte, mais à contrecœur, d'échanger la Dominique contre Tobago. ${ }^{105}$ C'est ainsi que le traité de paix, signé à Versailles en janvier 1783 et ratifié à Paris en septembre de la même année, cédait la Dominique à la Grande-Bretagne.

104 Fait intéressant à noter, un duel d'artillerie eut lieu le 4 janvier 1795 presque exactement au même endroit, entre le HMS Blanche qui patrouillait les eaux dominicaines sous le commandement du capitaine $R$. Faulkner, et la frégate française Pique. Après s'être canonnés pendant presque une heure à bout portant, les deux vaisseaux s'abordèrent. Le Blanche s'amarra au Pique qu'il traîna en se laissant pousser par le vent. Puis, afin que rien ne gêne son tir, le Blanche fit sauter délibérément son arrière et mitrailla le Pique de toutes ses pièces. Après un combat de sept heures au cours duquel Faulkner fut tué, le vaisseau français amena son pavillon. Un monument a été élevé à Faulkner et à son équipage dans la cathédrale St. Paul à Londres (St. Johnston, op. cit., 7).

105 Chadwick, op. cit., 248; John Fortescue, ed., A Selection from the Papers of King George III (Cambridge, 1927), I: 309, 332; II: 368, 375, 388, 402-403; Vincent T. Harlow, The Founding of the Second British Empire 1763-1793 (London, 1952), 378-379; Grenville à Fitzherbert, 29 décembre 1782, dans L.G.W. Legg, ed., British Diplomatic Instructions, 1689-1789 (London, 1934), VII: 213. Il est amusant de constater qu'en 1798, Andrew Johnstone, gouverneur de la Dominique, avait prévenu les législateurs chicaniers que le gouvernement anglais était fatigué de leur agitation et qu'il étudiait la possibilité d'échanger la Dominique contre Tobago (Lettre du $1^{\text {er }}$ décembre 1798 incluse dans la lettre de Knox à King, 19 avril, PRO, CO 71/30). 
En apprenant cette nouvelle, les administrateurs français des Antilles furent amèrement déçus. Il leur paraissait inconcevable qu'une île, que De Bouillé considérait si importante pour la sécurité et le commerce de la Martinique et de la Guadeloupe, soit ainsi abandonnée. ${ }^{106}$ Ayant foi dans l'avenir, ils envoyèrent en France un rapport qui avait sans doute été rédigé, à la demande des autorités, par M. Rallier, ingénieur à Roseau. Considéré comme "un rapport que l'on aura profit à consulter quand le moment viendra d'attaquer la Dominique", ce document décrivait en détail les ouvrages de défense de l'île et dressait la liste des résidents et des esclaves sur lesquels on pourrait compter, advenant une tentative de reconquête. ${ }^{107}$

C'est plutôt de mauvaise grâce que les Français se résignèrent à remettre la Dominique à la Grande-Bretagne. Quelques semaines avant que John Orde, nommé gouverneur de l'île, arrive pour prendre officiellement possession de cette colonie, deux vaisseaux de guerre britanniques transportant un régiment anglais firent leur apparition dans la baie de Roseau. Le gouverneur français refusa de livrer l'île, prétextant que les autorités de la Martinique ne lui avaient transmis aucune instruction à cet effet. On faillit en venir aux mains lorsque Edward Abbot, le commandant anglais, insista pour remplir sa mission. Il obtint finalement la permission de débarquer ses hommes à PointeMichel. Toutefois, le gouverneur interdit aux officiers britanniques de pénétrer dans la ville de Roseau et disposa des troupes autour de la baie, afin de prévenir une attaque surprise. Ce soir-là, la plupart des résidents anglais, hommes, femmes et enfants, se rendirent à pied ou à cheval à Pointe-Michel pour acclamer les soldats qui venaient de débarquer. Les Français furent encore plus contrariés lorsqu'ils virent les Anglais hisser chaque matin l'Union Jack, malgré les sommations réitérées du gouverneur. ${ }^{108}$

L'heure du départ approchant, les Français démolirent systématiquement les fortifications qu'ils avaient érigées et endommagèrent celles qui existaient avant leur arrivée, en faisant même sauter quelques-unes. Toutefois, à la demande d'Abbot,

${ }_{106}$ Mémoire sur la Dominique, 23 Fructidor, an 9, AN, Colonies $\mathrm{C}^{10} \mathrm{D}^{3}$.

107 Rallier, Mémoire, ANOM, Dessins et Mémoires, Carton II, n 143. Il existe une copie de ce rapport, ainsi que du mémoire de Thouvenot daté du 24 août 1786 et intitulé "Recherche sur le moyen de défense et d'attaque de la Dominique", dans les Archives du Ministère de la Guerre, Reconnaissances, plans, projets, Colonies européennes des Antilles, $n^{\circ} 1,669$.

108 Atwood, op. cit., 165-167. 
ils laissèrent intacts les magasins et les casernes. ${ }^{109}$ Le 8 janvier 1784, Orde apparut devant Roseau. A son grand dépit, les Français firent quelques difficultés futiles pendant deux jours et se livrèrent "à quelques actes de violence".110 Enfin, dans l'après-midi du 10 janvier, les troupes britanniques, qui avaient marché de Pointe-Michel à Roseau, entrèrent dans la ville au son d'une musique militaire. Au même moment, les Français quittaient Roseau sous les quolibets et les insultes de la population anglaise et s'embarquaient sur leurs navires. Alors, Orde débarqua d'une frégate, salué par les canons de fort Young. A cet endroit, des Dominicains en liesse avaient presque cassé le mât dans leur impatience à hisser le pavillon britannique. Au milieu des cris "Vive le Roi George", le nouveau gouverneur se fraya un chemin parmi la foule enthousiaste et se rendit au palais de justice prêter le serment d'office. Il alla ensuite à "une réception très digne, préparée à son intention par la colonie".111

Le retour à la domination anglaise consterna les Français de la Dominique. Un bon nombre d'entre eux, de même que plusieurs habitants de Saint-Vincent et de la Grenade, vendirent leurs biens et passèrent à Trinidad avec l'autorisation des Espagnols. ${ }^{112}$ La France continua à s'intéresser à la Dominique en suivant de près les fluctuations démographiques et économiques de l'île et en se tenant au courant de son système de défense. En 1795, Victor Hugues, plaçant son espoir dans les résidents français de la Dominique, tenta une invasion qui échoua. En 1805, une autre tentative ordonnée par Napoléon n'eut pas plus

${ }_{109}$ Procès-verbal de la Remise de l'Isle de la Dominique, 5 janvier 1784, AN, Colonies F3 44. Atwood ne fait pas mention de ce geste qui est à l'honneur des Français. D'ailleurs, ces derniers avaient présenté une requête semblable aux Britanniques lors de la capture de l'île en 1778, comme en fait foi l'Article 25 de l'Acte de capitulation. Les Français laissèrent plus d'entrepôts militaires à la Dominique que sur n'importe quelle autre île qqu'ils avaient évacuée (Orde à North, 20 février 1783, PRO, CO $71 / 8$ ).

110 Orde à North, 3 février 1784, PRO, CO 71/8.

111 Atwood, op. cit., 170.

112 Frances Armytage, The Free Port System in the British West Indies (London, 1953), 5-6; D. Murray, The West Indies and the Development of Colonial Government, 1801-1834 (Oxford, 1965), 67. Néanmoins, en 1793, les Français constituaient encore les deux tiers de la population dominicaine (Bruce à Dundas, 3 mars 1793, PRO, CO 71/24). En l'espace de dix ans, 15,000 pionniers catholiques avaient déménagé à Trinidad avec leurs esclaves et y avaient mis les Espagnols en minorité. 
de succès. ${ }^{113}$ La fin de la Révolution française mit un terme aux ambitions de la France de reconquérir la Dominique, mais des rumeurs de toutes sortes continuèrent de circuler dans l'île pendant tout le dix-neuvième siècle. ${ }^{114}$

Département d'histoire

JOSEPH-A. BOROMÉ

The City College of the City University

of New York

113 H. De Poyen-Bellisle, Les Guerres des Antilles de 1793 à 1815 (Paris, 1896), 99, 278-284.

114 Guillaume Thomas François Raynal, Histoire Philosophique et Politique des Etablissements et du Commerce des Européens dans les Deux Indes (Paris, 1820-1821), XII: 382. En 1854, quand l'Angleterre envisagea la possibilité de remettre certaines îles à la France, Charles Gordon Falconer, rédacteur du journal The Dominican, déclara que les habitants de la Dominique "aimeraient mieux mourir Anglais libres que de vivre sous le joug politique de la France" (The Dominican, 4 octobre 1854). En 1890, lorsque le bruit courut que la Grande-Bretagne pourrait céder la Dominique afin de régler le désaccord qui existait au sujet des droits de pêche à TerreNeuve, Theodore Righton, rédacteur du Dominican, exprima l'opinion que rares étaient les Dominicains qui favorisaient cette solution, parce que le gouvernement britannique était stable "depuis des siècles", tandis que celui de la France était "remarquable pour ses révolutions et ses changements" (The Dominican, 3 juillet, 24 juillet et 14 août 1890 ). Même en 1891 , les habitants de Vieille Case (région située dans la partie nord de la Dominique et où des Dominicains d'origine française vivaient presque à l'écart) adressèrent à $\mathrm{Sa}$ Majesté britannique une pétition dans laquelle ils demandaient que l'île soit remise à la France. Cette requête disparut mystérieusement avant même d'atteindre Roseau. Quelques fonctionnaires du Colonial Office à Londres déploraient l'absence d'unanimité sur cette question. Selon eux, tous les insulaires dominicains auraient dû demander le retour de l'île à la France puisque, compte tenu des facteurs d'ordre géographique, la Dominique "devrait redevenir française pour la troisième fois" (Wingfield et Meade, 31 mars et $1^{\text {er }}$ avril 1891, notes marginales d'une lettre de HaynesSmith à Knutsford, 9 mars 1891, PRO, CO 152/180). En 1893, alors qu'il témoignait devant sir Robert Hamilton, commissaire royal, un notable de la Dominique, A.R. Lockhart, affirma que les Dominicains seraient plus heureux et plus prospères s'ils étaient gouvernés par la France, surtout parce qu'ils étaient plus Français qu'Anglais "dans leur façon de voir, de sentir et de prier" (Great Britain, Report of the Royal Commission, 1894, xxxiii). Cependant, aucun autre Dominicain en vue ne partageait cette opinion. Néanmoins, l'historien James Anthony Froude était de cet avis, soutenant que la Dominique "n'était anglaise que de nom" (Froude, The English in the West Indies (London, 1909), 128, 142). 